\title{
Exploring Formative Assessment Possibilities: Building a 'Teamwork Discourse' with First-Year Engineering Students Online
}

\author{
Lauren Senna Fouché, Erika Müller \\ EBIT ENGAGE, University of Pretoria, South Africa.
}

\begin{abstract}
Effective teamwork is one of the Engineering Council of South Africa's (ECSA) exit-level outcomes. To achieve this outcome, one has to learn specific discourses and behaviours related to teamwork. Professional Orientation is a first-year engineering module offered in an extended engineering degree programme at a residential university in South Africa. This module assists students in developing a 'teamwork discourse', using engineering-based projects that follow the CDIO framework. In 2020, these projects transitioned fully to a virtual environment due to Covid-19 restrictions. The iPeer Learning Management System tool for peer-and self-assessment was used in this research to investigate whether first-year students were able to apply the teamwork discourses taught to them when completing the projects online. A quantitative analysis of the iPeer results reflected that while $54 \%$ of the students remained consistent in the two projects, $16 \%$ showed an improvement, and 30\% showed a decrease. The reasons for these results could be varied. Thus, a qualitative analysis of the students' comments for increased and decreased marks was also conducted to assess how the relevant teamwork discourses were applied and to what extent. These findings confirmed that teamwork discourses could effectively be applied by a smaller percentage of first-year students.
\end{abstract}

Keywords: Teamwork; engineering; projects; first-year; formative assessment. 


\section{Introduction}

\subsection{Background}

The University of Pretoria, South Africa, offers a five-year extended engineering degree programme. In the first-year of this programme a skills- and practices-based module titled Professional Orientation is offered to students. The aim of this module is to provide students with the foundations on which to build the relevant academic, IT, reading, writing and problem-solving literacies needed to succeed in their studies and later in the workplace. One of the academic literacies taught in the module is teamwork, both because it is outlined as an exit-level outcome by ECSA (2020) and because it helps students to develop the situated and transformed social practices, theorized in New Literacies Studies (Cope \& Kalantzis, 2000) that will aid them in their personal and professional development.

Teamwork involves a complex mix of verbal and non-verbal communication behaviours, or discourses, to be achieved successfully. Consequently, this aspect of Professional Orientation is scaffolded to help students first understand and then apply knowledge and skills to projects that represent an engineering environment in microcosm. In the first semester, students participate in workshops on teamwork, effective communication, conflict management, collaborative learning, and $\mathrm{CDIO}^{1}$. These offer the students a theoretical understanding of how to work effectively in teams. In the second semester, students apply what they engaged with in semester one to projects that follow the CDIO framework. The first is the GoGreen project, where students are put into pre-selected teams, from a variety of different engineering disciplines, to practice applying the teamwork discourses they were taught in the first semester for the first time. The second project is the capstone project titled 'LEGO', where students are put into new pre-selected teams, still from different engineering disciplines, to reinforce the teamwork discourses they have learnt and practiced in a multidisciplinary environment that more closely emulates a workplace environment.

At the middle and end of each project, students use the iPeer Learning Management System (LMS) tool to grade the performances of each of the team members for assessment 'as learning'. This allows students to reflect on their own learning and to offer useful feedback to their teammates with the aim of improving their teamwork as they go along.

\subsection{Rationale}

Educators and scholars generally recognise that high levels of teamwork are necessary to be successful in today's workplace. Although also highly valued by organisations that need cooperation between members in order to achieve their objectives, engineering programmes

\footnotetext{
${ }^{1} \mathrm{CDIO}$ is a project framework used by engineers that subdivides the lifecycle of a project from conception to completion into four categories: Conceive, Design, Implement, and Operate.
} 
seldom pay explicit attention to "helping students develop teamwork and project management skills" (Smith, 2000). Limited instruction is provided on how to communicate and function effectively as a member of a team. Often engineering education focuses on individual contributions rather than on managed group efforts, although such groups are the norm in industry. It is therefore important that students studying engineering "learn skills for working effectively as members of groups" (Denning, 1992). However, Lingard (2010) acknowledges that most engineering students are ill prepared to function effectively in teams before being required to do so as part of a course, which aligns with the researchers' experience.

Furthermore, the National Academy of Engineering (2020) in the United States (recognized by the University of Pretoria because of its affiliation with the Washington accord) notes that only 40 to $60 \%$ of entering engineering students persist and successfully complete an engineering degree. To address this issue, it is becoming increasingly recognised that it is important to introduce engineering activities, including team-based design projects and community service projects, early in the undergraduate experience alongside basic science and maths courses so that students begin to develop an understanding of the essence of engineering as soon as possible. Curricular approaches that engage students in team activities in team design courses, and in courses that connect engineering design and solutions to realworld problems so that the social relevance of engineering is apparent, appear to be successful in retaining students. However, the design of such approaches and assessment of their effectiveness in terms of how to evaluate individual student performance are still not well rooted in rigorous investigation.

Finding effective teaching strategies and meaningful ways of assessing teamwork are further challenging tasks, according to Lingard (2010). Thus, the researchers elected to additionally focus on the formative feedback in self- and peer-assessment to determine if this might contribute to an improvement in teamwork and engagement amongst first-year engineering students.

\subsection{Aims and Objectives}

Due to the Covid-19 pandemic in 2020, the GoGreen and LEGO projects took place virtually using computer-based tools. The study that is reported and discussed in this paper investigated whether first-year engineering students were able to:

- $\quad$ use the iPeer LMS tool to reflect on their peer and their own application of knowledge and understanding of teamwork discourses first to the GoGreen project.

- reinforce and improve their knowledge, understanding, and experience of teamwork discourses, again using iPeer, in the capstone LEGO project. 


\section{The Projects}

The GoGreen and LEGO projects that are offered in the second semester of Professional Orientation were adapted to accommodate the online learning environment. A description of these projects and an explanation of how they were adapted is offered in this sub-section.

\subsection{GoGreen}

The GoGreen project runs throughout the second semester of Professional Orientation. The aim of this project is for students to work in teams to create a project, product, or game out of a recyclable material that can be used to encourage a community to reduce, reuse, and recycle. In previous years, teams were peer-selected and comprised four students so that they could practice their teamwork in a comfortable and familiar environment. Teams were also told which material they would work with (for example, plastic, electronic waste, or tin cans) and to actively engage with a community to spread awareness. In 2020 these aspects of the project were amended as follows:

1. Students worked in teams of three, rather than four.

2. Students were pre-assigned teammates by the lecturers in the module.

3. Each team could select the material they would like to work with, based on what they had available at home.

4. The teams were encouraged to spread awareness online, rather than through active engagement with a community.

It was decided that smaller teams would make the teamwork aspect of the project more manageable, and that the teams would need to be pre-assigned to ensure that students would neither be advantaged nor disadvantaged by their access to resources. Additionally, students needed to have access to the material they would work with and they would need to limit their contact with people as much as possible, due to the pandemic. Outside of these changes, the project lifecycle and assessments remained the same.

\subsection{LEGO}

The LEGO project is introduced to the students during the implementation phase of the GoGreen project. Students are expected to manage their time around these projects and apply their experience from the GoGreen project to the LEGO project. Historically, the LEGO project takes place face-to-face. This project requires students to design and build a crane out of LEGO pieces that can lift the maximum amount of weight $10 \mathrm{~cm}$ in 90 seconds. The teams are required to conduct research, complete a design defence, build and test their crane, and report back on their final design. However, the building and testing element of the project 
had to be adapted to accommodate the online learning environment. Thus, the following changes were made:

1. Students worked in teams of three, rather than four.

2. The emphasis of the project shifted from manufacturing to design.

As a replacement for the building and testing phase of the project, the students used Mecabricks free online software to develop the concept that they had established as a team Mecabricks is an online LEGO brick software that allows one to develop one's concept into a 3D LEGO design. In the design phase of the project, the students defended their initial hand drawn concept, including calculations, to a team of peers and panelists from the module. Then, they used the feedback to develop their design further in Mecabricks - a document specifying the number of pieces and types of pieces the students could use was provided at the start of the project. Once the designs were finalized, each team was given access to all of the designs and asked to compare their team's design to another team's design by taking the specifications and calculations into consideration. In this way, the students were forced to think critically about their design work.

\section{Method}

A total of four iPeer assessments were completed in the two projects. These assessments were done after the conceive and design phase of each project, and again after the implement and operate phases of the projects. iPeer is an anonymous online LMS tool whereby students receive a rubric (created by the lecturer to assess select aspects of teamwork). The students then award their teammates a mark and offer a comment to support the mark. At the end of the rubric, a general comment is required. Comments are compulsory, and the system prevents students from submitting incomplete evaluations.

Because these iPeer evaluations are subjective and used to evoke honest, reflective responses, the results were used to identify the students who showed an increased performance / achievement or a decreased performance / achievement from the GoGreen to the LEGO project. Once these students were identified, the comments were used to ascertain why there was an improvement or a drop in the result, and if this could suggest that the students had started to apply the teamwork discourses they were taught in workshops in the first semester to their practical teamwork experience in the second semester, and to identify if this application improved from GoGreen to LEGO based on the assessment 'as learning' from themselves and their peers.

After organizing the comments received by the identified students into documents titled: GoGreen increases, GoGreen decreases, LEGO increases, and LEGO decreases, codes based on the areas assessed in the rubrics were identified. The two researchers then did solo coding 
using the CAQDAS software program Atlas.ti for qualitative analysis and in a second round of coding worked collaboratively to compare results and ensure intercoder agreement. Thereafter, the codes were organized thematically based on the teamwork discourses taught in the first semester. These themes were identified as: communication, time management, personal contribution, openness and understanding, commitment to the team goal, and personal insight. The results are discussed in the section that follows.

\section{Results and Discussion}

\subsection{Preliminary Observations and Participant Selection}

Overall, the students' iPeer scores were inflated compared to the overall results for each project. Table 1 shows the percentage difference between the overall and iPeer averages for the GoGreen and LEGO projects.

Table 1. GoGreen and LEGO differences.

\begin{tabular}{lcc}
\hline & GoGreen (\%) & LEGO (\%) \\
\hline iPeer average & 94 & 90 \\
Overall project average & 62 & 67 \\
Percentage difference & 32 & 23 \\
\hline
\end{tabular}

These results are not unusual as students tend to inflate their own and their peers results due to concern that it might negatively impact the module mark. A limited understanding of the importance of teamwork discourses both at university and in a professional environment might also lead to inflated results. Although, it is interesting to note that the overall LEGO project average, the more challenging capstone project, was 5\% higher than the GoGreen project average, and that the GoGreen iPeer average was $4 \%$ higher than the LEGO iPeer average. This could suggest that, on average, the students' teamwork improved from the first to the second project and that the students began to apply their understanding of the importance of teamwork discourses to their iPeer results, resulting in a drop in the average. However, this is not a conclusive finding and further analysis of quantitative data is planned in later stages of this longitudinal study.

Of the 99 students who qualified for the study, 54\% stayed within a 5\% range from GoGreen to LEGO, $16 \%$ increased by more than $5 \%$, and $30 \%$ decreased by more than $5 \%$. Clear-cut assumptions regarding the increases and decreases in these results could not be made as an improvement would not strictly suggest better implementation of teamwork discourses and a decrease or drop may not suggest a diminishment in one's application of the teamwork discourses taught to them. In fact, an improved score could point to less critical and more general feedback (negative) and a decreased score could suggest more nuanced self- or peer- 
reflection (positive). To establish the possible reasons for the increase and decrease in results, a qualitative analysis of the relevant students' self- and peer-assessment comments was conducted. The most pertinent findings are discussed in the sub-section that follows.

\subsection{Qualitative Analysis}

The majority of the responses to each of the six categories, namely: communication, time management, personal contribution, openness and understanding, commitment to the team goal, and personal insight, become more positive in the increases and negative in the decreases from GoGreen to LEGO. This indicates that there is alignment between the results the students give themselves and their peers and their comments.

In the increases, time management is the only category that shows a small discrepancy between negative and positive comments (more negative than positive), which could be interpreted as students generally finding time management a challenge early in their university studies, sparking greater awareness and criticism. The virtual environment and flexible deadlines may have made this a greater challenge for students as well, as teams may have had difficulty arranging meeting times that were suitable to all participants. This is also apparent in the decreases as there was a $16 \%$ increase in negative comments for time management, also signifying that the challenges mentioned previously may be true.

With regard to communication, the negative and positive comments are relatively balanced in the students who show an improvement and the students who show a decrease - the largest range was in the LEGO decreases (35\% positive and $65 \%$ negative), suggesting that communication is a challenge for many students. This may be because they are still learning how to communicate effectively and work in teams. Moreover, the virtual environment would have made it more challenging for students to communicate as they had to rely on virtual platforms to contact one another and participate equally in the project.

Openness and understanding and commitment to the team goal result in no negative feedback in the LEGO project increases, showing that these students demonstrate growth in their willingness to work with diverse groups of people, especially since they were put into preselected teams by their lecturers, and a willingness to work toward a collective goal. However, there is a decrease in openness and understanding and commitment to the team goal when it comes to the decreases. Although the results are still overly inflated $(83 \%$ positive and $17 \%$ negative and $91 \%$ positive and $9 \%$ negative, respectively), this may be a sign of poor input or someone 'taking over' the project as a result of ongoing communication challenges.

In terms of personal insight, many students tended to offer a self-reflection that was representative of their peer feedback, an indicator of good insight and personal reflection. However, a portion of the students were still unable or unwilling to reflect on themselves as 
part of a team, a finding that is linked to student maturity. It was interesting to note that the students who showed a decrease in results from GoGreen to LEGO offered more positive personal insight than the students who showed an increase. This could suggest recognition of one's limitations as a teammate.

\section{Conclusion}

The students' formative feedback indicates that time management and communication remain areas of need, despite workshop interventions in the first semester. This suggests that practical experience and formative feedback that highlight these aspects of teamwork are valuable. Furthermore, the results indicate that first-year students can be exposed to teamwork early in their studies. Although teamwork results are inflated, students are able to identify how effectively teamwork discourses have been implemented by themselves and their peers. This emphasizes the need to actively teach these discourses and to use formative assessments to bring greater awareness to what it means to be an effective team member.

The transition from a face-to-face environment to a virtual environment was a challenging one for both the lecturers and students in Professional Orientation, and the finding that teamwork can be taught and can develop in this space is encouraging for the future. Thus, the researchers of the study at hand intend to extend their investigation on teamwork in firstyear engineering students to include the possible impact of other non-cognitive factors, such as personality, on teamwork.

\section{References}

Cope, W. \& Kalantzis. (2000). Multiliteracies: literacy learning and the design of social futures. Oxon, NY: Routledge.

Denning, P. J. (1992). Educating a new engineer. Communications of the ACM, 35(12), 8397). doi-org.uplib.idm.oclc.org/10.1145/138859.138870

Engineering Council of South Africa. (2020). Ensuring the expertise to grow South Africa: qualification standard for Bachelor of Engineering Technology (BEng Tech); NQF level $7 . \quad$ https://www.ecsa.co.za/ECSADocuments/Shared\%20Documents/E-02PT\%20Qualification\%20Standard\%20for\%20Bachelor\%20of\%20Engineering\%20Tech nology\%20(BEng\%20Tech)\%20NQF\%20Level\%207\%2020.pdf

Lingard, R.W. (2010). Teaching and assessing teamwork skills in engineering and computer science. Journal of Systemics, Cybernetics and Informatics, 8, 34-37.

National Academy of Engineering. (2020). Educating the engineer of 2020: adapting engineering education to the new century. Washington, DC: The National Academies Press. 
Smith, K. A. (2000). Strategies for developing engineering student's teamwork and project management skills. ASEE Annual Conference Proceedings, 5.555.1-5.555.12. doi.org/10.18260/1-2--8709 